\title{
MARKET CONCENTRATION, MULTI-MARKET PARTICIPATION AND MERGERS IN NETWORK INDUSTRIES
}

\author{
DENNIS L. WEISMAN * \\ Department of Economics, Kansas State University
}

\begin{abstract}
We use a Cournot model with complementary demands to derive sufficient conditions for mergers that increase market concentration and multi-market participation to lower prices, raise industry profits and hence increase economic welfare. Notably, these findings do not depend upon the realization of merger economies. This analysis may have special relevance for mergers in network industries, including the telecommunications and transportation industries, wherein policymakers have expressed concern about recent consolidation trends.
\end{abstract}

\section{Introduction}

Consider a merger between two firms that simultaneously increases both market concentration and multi-market participation. A merger of this type gives rise to two separate effects. The first effect is an increase in market concentration that places upward pressure on market price, ceteris paribus. The second effect is an increase in multi-market participation that compounds the upward pressure on market price in the case of substitutes, and exerts countervailing downward pressure on market price in the case of complements. Complementary demands are typical in network industries because an increase in traffic flows from one node to another node on a telecommunications or transportation network generates an increase in traffic flows in the reverse direction and to other nodes on the network as well.

The specific problem under analysis can be illustrated with the aid of Figure 1. There are assumed to be four separate markets, A, B, C and D, and four market providers, 1, 2, 3, and 4. A merger is proposed between provider 1 and provider 2. This merger simultaneously increases concentration in markets $\mathrm{A}$ and $\mathrm{C}$ and increases multi-market participation in markets $\mathrm{B}$ and $\mathrm{D},{ }^{1}$ thereby giving rise to the countervailing effect on prices discussed above.

* Department of Economics, Kansas State University, Waters Hall Manhattan, KS 66506-4001. Email: weisman@,ksu.edu The author is grateful to an anonymous referee and the editor, Julian Wright, for constructive suggestions for revision and to Mark Jamison, Alfred Kahn, Michael Klass, Dale Lehman, David Sappington, Lester Taylor and Roger Woock for helpful discussions. The usual caveat applies.

${ }^{1}$ In markets B and D, there is one multi-market provider, pre-merger, and two multi-market providers, postmerger. 


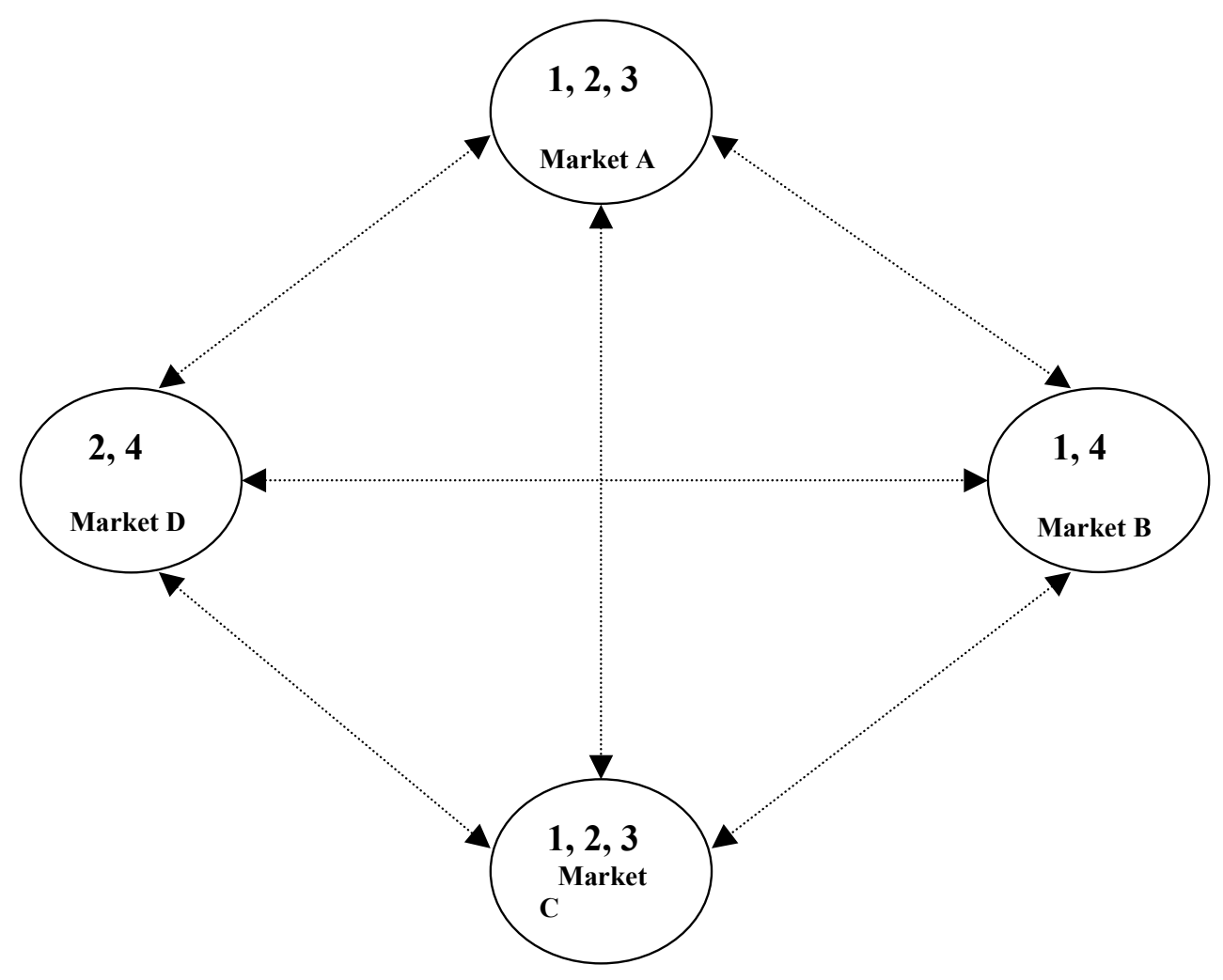

Figure 1: Network traffic flows

Weisman (2003) shows that mergers that increase both market concentration and multimarket participation can yield non-increasing prices when demands are complementary. The framework employed in his analysis was restricted to one in which the market was served exclusively by either single-market providers (SMPs) or multi-market providers (MMPs). This paper develops a more general framework for evaluating mergers when SMPs and MMPs operate simultaneously in the market. We derive sufficient conditions for mergers that increase both market concentration and multi-market participation to lower prices, raise industry profits and hence be welfare-enhancing. These findings do not depend upon the realization of merger economies.

This analysis in this paper differs from Farrell and Shapiro (1990) in that the source of the welfare gains from increased consolidation does not depend on the realization of merger synergies, but rather on the recognition of demand complementarities. Nonetheless, the parallels are noteworthy. For example, welfare can rise with market concentration in the Farrell and Shapiro framework if demand is redistributed from relatively inefficient to relatively efficient firms. In this analysis, welfare can rise with market concentration if demand is redistributed from SMPs to MMPs. This occurs because the effective "super elasticity" confronting the MMPs in the case of complementary demands is higher than the own price elasticity confronting the SMPs.

Jamison (2002) was one of the first to recognize the possibility that mergers that internalize network externalities can raise welfare despite an increase in market 
concentration and the absence of merger economies. ${ }^{2}$ In similar fashion to Jamison, this paper employs a Cournot framework with complementary demands to evaluate the welfare effects of mergers. This work differs from Jamison in three respects. First, we derive an actual measure of the marginal rate of substitution of MMPs for market providers such that prices are non-increasing, post-merger. Second, we derive (closed-form) sufficient conditions for a merger that simultaneously increases market concentration and multimarket participation to be welfare-enhancing. Finally, we do not explicitly consider the endogenous choice of product quality or the manner in which a merger may influence quality.

A literature related to multi-market mergers is that of multi-market contacts (Bernheim and Whinston, 1990; Hughes and Oughton, 1993; Evans and Kessides, 1994). ${ }^{3}$ This literature investigates the manner in which cross-market contacts between firms may serve to facilitate collusive market outcomes. In a related context, Philips and Mason (1996) examine the influence of multi-market contacts in a regulatory setting. Specifically, they explore the manner in which a tighter price cap in market $\mathrm{X}$ affects output in market $\mathrm{Y}$.

The format for the remainder of this paper is as follows. The basic model and main findings are developed in Section 2. The policy implications of this analysis are presented in Section 3. Section 4 briefly summarizes the main findings and concludes.

\section{The model}

To investigate the problem of interest, we employ a Cournot model with complementary demands in which SMPs and MMPs may serve the market simultaneously. ${ }^{4}$ The novel dimension of this analysis is not the Cournot framework per se, but rather the closed-form solutions for prices and outputs that facilitate an equilibrium analysis of welfare-enhancing mergers when demands are complementary.

Suppose that there are two identical markets - market A and market B. The inverse demand functions for these two markets are given by

$$
\begin{aligned}
& P^{A}=\alpha-\beta Q^{A}+\gamma Q^{B} \text { and } \\
& P^{B}=\alpha-\beta Q^{B}+\gamma Q^{A}
\end{aligned}
$$

where $\alpha>0, \beta>\gamma>0, Q^{A}=(n-k) q_{s}^{A}+k q_{m}^{A}$ and $Q^{B}=(n-k) q_{s}^{B}+k q_{m}^{B}$. The fact that demands and marginal costs are linear and the markets are symmetric implies that there is a unique equilibrium and that it is symmetric. Hence, $q_{s}^{A}=q_{s}^{B}$ and $q_{m}^{A}=q_{m}^{B}$ in equilibrium.

\footnotetext{
${ }^{2}$ In a related context, Weisman (1999) shows that mergers in the telecommunications industry may be procompetitive because the larger footprint of the merging firms provides greater incentives for entry into outof-region markets, ceteris paribus. That is to say, mergers enable telecommunications providers to internalize network externalities.

${ }^{3}$ See Bulow et. al and Cabral and Villas-Boas (forthcoming) for an analysis of multiproduct oligopoly. This research is principally concerned with intra-firm product interaction when demands are interdependent. See also Champsaur and Rochet (1989).

${ }^{4}$ See Economides and Salop (1992) for a modern treatment of Cournot competition with complementary demands.
} 
The profit functions for the representative SMP and MMP in market A (market B) are given, respectively, by

(3) $\Pi_{s}^{A}=q_{s}^{A}\left[\alpha-\beta Q^{A}+\gamma Q^{B}-c\right]$, and

(4) $\Pi_{m}^{A}=q_{m}^{A}\left[\alpha-\beta Q^{A}+\gamma Q^{B}-c\right]+q_{m}^{B}\left[\alpha-\beta Q^{B}+Q^{A}-c\right]$.

Recognizing that $q_{s}^{A}=q_{s}^{B}$ and $q_{m}^{A}=q_{m}^{B}$ in equilibrium and assuming an interior solution, the Cournot-Nash equilibrium quantities are defined implicitly by the solution to the following first-order conditions:

$$
\begin{aligned}
& q_{s}^{A}:[(\gamma-\beta)(n-k)-\beta] q_{s}^{A}+k(\gamma-\beta) q_{m}^{A}=c-\alpha, \text { and } \\
& q_{m}^{A}:[(\gamma-\beta)(n-k)] q_{s}^{A}+[(\gamma-\beta)(k+1)] q_{m}^{A}=c-\alpha .
\end{aligned}
$$

To focus explicitly on the relationship between own and cross-effects, let $\beta=\theta \times \gamma$, where $\theta>1$. The following proposition establishes that the output of the MMP exceeds that of the SMP in equilibrium, ceteris paribus.

Proposition 1. If $\alpha \geq c$ and $\theta>1$, then the unique Cournot-Nash equilibrium is given by (5) and (6). If $\theta \leq 1$, then no equilibrium exists.

Proof: Solving (5) and (6) using Cramer's rule yields:

(7) $q_{s}^{A *}=\frac{[\alpha-c][\theta-1] \gamma}{|Z|}$, and

$$
q_{m}^{A *}=\frac{[\alpha-c][\theta \gamma]}{|Z|}
$$

where $|Z|=\gamma^{2}[\theta-1][(n-k)(\theta-1)+\theta(k+1)]$ is the determinant of the coefficient matrix associated with the linear system in (5) and (6).

Substituting (7) and (8) into (1) or (2) and omitting superscripts since the markets are identical yields the equilibrium market price, or

$$
P^{*}=\alpha-\frac{[\alpha-c][(n-k)(\theta-1)+\theta k]}{\theta(n+1)-(n-k)}
$$

\footnotetext{
${ }^{5}$ See Tirole (1988, p.70) for the pricing rule for a (price-setting) multi-product monopolist with interdependent demands.
} 
It is immediate from (9) that the equilibrium market price is decreasing in the number of market providers $(n)$ and the number of MMPs $(k)$, ceteris paribus. In the next proposition, we identify the precise nature of the trade-off between $n$ and $k$.

Proposition 2. $-\left.\frac{d n}{d k}\right|_{d P^{*}=0} \geq 1$ in the equilibrium defined by (5) and (6) iff $\theta \in(1,2]$.

Proof: Taking the total differential of (9) with respect to $n$ and $k$, setting the resulting expression equal to zero, and simplifying yields

(10) $-\left.\frac{d n}{d k}\right|_{d P^{*}=0}=\frac{\gamma}{(\theta-1) \gamma}=\frac{1}{\theta-1}$.

Since $n$ and $k$ are integers, a merger that results in both a reduced number of market providers and an increased number of MMPs with market price remaining unchanged satisfies

(11) $\frac{1}{\theta-1} \geq 1 \Rightarrow \theta \in(1,2]$.

Proposition 2 provides the marginal rate of substitution of MMPs for market providers. In order for this trade-off to exist, $1<\theta \leq 2$. Hence, for cross-effects that are "sufficiently large," mergers that increase market concentration do not necessarily cause prices to rise, even in the absence of merger economies.

The following two propositions derive conditions under which industry consolidation results in non-increasing prices and non-decreasing profits, respectively.

Proposition 3. Let the initial market structure be given by $n>1$ SMPs and $k \geq 0$ MMPs, where $n-k \geq 2$. Suppose that $\Delta n=-1$ and $\Delta k=+1$, then if $\theta \in(1,2]$ in the equilibrium defined by (5) and (6), $\Delta P=-\frac{d P}{d n}+\frac{d P}{d k} \leq 0$, with the inequality holding strictly for $\theta \in(1,2)$.

Proof: Computing $\Delta P$ from (9) and simplifying yields

$$
\Delta P=\frac{[\alpha-c][\theta][\theta-2]}{[\theta(n+1)-(n-k)]^{2}} \leq 0
$$

for $1<\theta \leq 2$ upon appeal to Proposition 1 .

The existence of an equilibrium requires that $\theta>1$, so we focus on the condition that $\theta \leq 2$. Recall that $\theta$ captures the relationship between own and cross-effects. To provide the economic intuition underlying Proposition 3, note that if $\theta$ is sufficiently large, the price-increasing effect associated with decreasing $n$ dominates the price-decreasing effect of increasing $k$. This is the rationale for the upper bound on $\theta$.

Recognizing that the two markets are symmetric, total industry profits are given by 
(13) $\Pi=2(n-k) \Pi_{s}+k \Pi_{m}$,

where the reduced-form profit functions for the representative SMP and MMP are given, respectively, by

(14) $\Pi_{s}(n, k)=\frac{\theta[\alpha-c]^{2}}{\gamma[\theta(n+1)-(n-k)]^{2}}$, and

$$
\Pi_{m}(n, k)=\frac{2 \theta^{2}[\alpha-c]^{2}}{\gamma[\theta-1][\theta(n+1)-(n-k)]^{2}}
$$

Proposition 4. Let the initial market structure be given by $n>1$ SMPs and $k=0$ MMPs. Suppose that $\Delta n=-1$ and $\Delta k=+1$, then in the equilibrium defined by (5) and (6),

(i) $\Delta \Pi=-\frac{d \Pi}{d n}+\frac{d \Pi}{d k}>0 \Rightarrow \theta \in\left(1, \frac{n-k}{n-1}\right)$ or $\theta>2$;

(ii) $\Delta \Pi=-\frac{d \Pi}{d n}+\frac{d \Pi}{d k}=0 \Rightarrow \theta=\frac{n-k}{n-1}$ or $\theta=2$.

Proof: The interval $\left(1, \frac{n-k}{n-1}\right)$ is non-degenerate iff $k=0$. Using (14) and (15), computing $\Delta \Pi$ and simplifying yields

$$
\Delta \Pi=\left[\frac{2 \theta[\alpha-c]^{2}}{\gamma[\theta(n+1)-(n-k)]^{2}}\right] \times\left[\frac{2-\theta}{\theta-1}\right] \times\left[\frac{\theta(1-n)+n-k}{\theta(n+1)-(n-k)}\right]
$$

The first term on the RHS of (16) is strictly positive. The signs of the second and third terms on the RHS of (16) take on the signs of their respective numerators since $\theta>1$ in equilibrium by Proposition 1. It follows that

$$
\operatorname{sgn}\{\Delta \Pi\}=\operatorname{sgn}\{2-\theta\} \times \operatorname{sgn}\{\theta(1-n)+n-k\}
$$

The proof of (ii) follows from the fact that $\Delta \Pi=0$ for $\theta=2$ or $\theta=\frac{n-k}{n-1}$. The proof of (i) requires that the two cases of $\theta<2$ and $\theta>2$ be examined. In the case of $\theta<2$, $\operatorname{sgn}\{\Pi\}>0 \Rightarrow \operatorname{sgn}\{\theta(1-n)+n-k\}>0, \quad$ or $\quad \theta<\frac{n-k}{n-1} . \quad$ In the case of $\theta>2$, $\operatorname{sgn}\{\Delta \Pi\}>0 \Rightarrow \operatorname{sgn}\{\theta(1-n)+(n-k)\}<0, \quad$ or $\quad \theta>\frac{n-k}{n-1}, \quad$ which is implied by $\theta>2$ since $\frac{n-k}{n-1} \leq 2 \forall n>1$ and $\forall n \geq k \geq 0$. 
Proposition 2 provides sufficient conditions for the proposed change in market structure to increase industry profits. There are two cases of interest. If the change in industry structure yields a decrease in market price $(\theta<2)$, then the increase in industry output must be sufficiently large to increase overall industry profits. If the change in industry structure yields an increase in market price $(\theta>2)$, then the decrease in industry output must not be so large as to reduce overall industry profits.

Finally, observe that $\frac{n-k}{n-1}$ is monotonically decreasing in $n$ at $k=0$ and therefore the interval $\left(1, \frac{n-k}{n-1}\right]$ grows larger with fewer market participants. This implies that industry consolidation and multi-market participation have a more pronounced effect on industry profits when there are a relatively small number of market participants.

The following proposition establishes sufficient conditions for industry consolidation to be welfare-enhancing.

Proposition 5. Let the initial market structure be given by $n>1$ SMPs and $k=0$ MMPs. Suppose that $\Delta n=-1$ and $\Delta k=+1$, then if $\theta \in\left(1, \frac{n-k}{n-1}\right]$ in the equilibrium defined by (5) and (6), (i) $\Delta H>0$; (ii) $\Delta P \leq 0$; and (iii) $\Delta \Pi \geq 0$ with the inequalities holding strictly for $\theta \in\left(1, \frac{n-k}{n-1}\right)$.

Proof: The proof for (i) follows directly from (7) and (8). Industry consolidation that yields non-increasing (respectively, decreasing) prices requires that $\theta \in(1,2]$ (respectively, $\theta \in(1,2)$ ) from Proposition 3. Industry consolidation that yields non-decreasing (respectively increasing) profits requires that $\theta \in\left(1, \frac{n-k}{n-1}\right]$ or $\theta \geq 2$ (respectively, $\theta \in\left(1, \frac{n-k}{n-1}\right)$ or $\left.\theta>2\right)$ from Proposition 4. It follows that a merger that yields nonincreasing prices and non-decreasing industry profits satisfies

$$
\theta \in(1,2] \cap\left(1, \frac{n-k}{n-1}\right]=\left(1, \frac{n-k}{n-1}\right]
$$

since $\frac{n-k}{n-1} \leq 2 \forall n>1$ and $\forall n \geq k \geq 0$. Finally, to complete the proofs for (ii) and (iii), a merger that yields strictly decreasing prices and strictly increasing industry profits satisfies

$$
\theta \in(1,2) \cap\left(1, \frac{n-k}{n-1}\right)=\left(1, \frac{n-k}{n-1}\right)
$$

A sufficient condition for economic welfare to be non-decreasing is that both the nonincreasing price condition of Proposition 3 and the non-decreasing profit condition of Proposition 4 hold simultaneously. This, in turn, requires that (i) $1<\theta \leq 2$ and (ii) 
$1<\theta \leq \frac{n-k}{n-1}$. Since $\frac{n-k}{n-1} \leq 2$ for all $n \geq 1$, condition (ii) is a sufficient condition for welfare to be non-decreasing, post-merger.

The following is an example of welfare-enhancing industry consolidation that satisfies the conditions of Proposition 5.

\section{Example 1.}

For the demand system in (1) and (2), let $\alpha=20, \mathrm{c}=2, \beta=2$ and $\gamma=1.6$. Suppose that $\mathrm{n}$ $=3$ and $\mathrm{k}=0$ so that there are initially 3 SMPs and 0 MMPs operating in each market. Observe also that (19) is satisfied since $\theta=1.25 \in(1,1.5)$. The equilibrium output of each SMP is 5.625 and total output in each market is 16.875 . The Herfindahl-Hirschman Index in each market is 0.3333 . The market price is 13.25 and industry profits are 380 . Following consolidation, $\mathrm{n}=2$ and $\mathrm{k}=1$. The equilibrium output of the SMP and the MMP in each market are 4.091 and 20.455, respectively. Total output in each market is 24.545 . The Herfindahl-Hirschman Index rises to 0.7222 , market price decreases to 10.182 and industry profits increase to 401.65 .

\section{$3 \quad$ Policy implications}

The findings of this analysis may be applied to mergers in network industries, ${ }^{6}$ including telecommunications (Lehman and Weisman, 2000; Dreazen, 2002), ${ }^{7}$ commercial airlines (Morrison and Winston, 2000), ${ }^{8}$ and railroads (Grimm and Winston, 2000; Park et. al., 2001). In each of these industries, the United States Government has recently expressed concerns about increasing levels of market concentration and potentially adverse effects on consumer welfare.

With respect to the telecommunications industry, and wireless telecommunications, in particular, the industry appears poised for significant consolidation as market providers seek to expand the size of their footprint. . There are currently five wireless telecommunications providers in the U.S. with a "national footprint," 10 and a large number of non-national or regional providers. ${ }^{11,12}$ It is anticipated that any wholesale movement to

\footnotetext{
${ }^{6}$ This is not to suggest that the applications discussed herein are necessarily restricted to network industries. Consider, for example, the possibility that consumption of a particular good in one market increases the likelihood of consumption of that good in another market.

${ }^{7}$ Empirical demand analysis in the telecommunications industry confirms the existence of demand complementarities in the form of point-to-point traffic patterns. See, for example, Taylor (1994) and Larson et. al. (1989).

${ }^{8}$ These findings may have implications not only for mergers, but also for alliances between commercial airlines. For example, Brueckner and Whalen (2000) found that international alliances can reduce interline airfares without necessarily raising fares in those markets in which the alliance partners compete directly. In addition, mergers between air transport companies can serve to increase the number and frequency of flights. In this case, the merger can serve not only to reduce prices, but to increase quality as well. See Jamison (2002) for an analysis of how mergers can lead to enhanced quality.

${ }^{9}$ The recent merger between AT\&T Wireless and Cingular created the largest cellphone provider in the U.S. See Latour et al. (2004), The Wall Street Journal (2004) and FCC (2004B). See also Baranes and Flochel (2003).

${ }^{10}$ These are Cingular, Nextel, Sprint PCS, T-Mobile, and Verizon Wireless. See FCC (2004A, ๆ 36).

${ }^{11}$ These carriers collectively operate 3,123 wireless systems in the U.S. and serve in excess of 171 million subscribers as of November 5, 2004. See CTIA at http://www.ctia.org/and CTIA (2004).
} 
consolidate would invite antitrust scrutiny as policymakers may be concerned that higher levels of concentration will lead to higher prices. ${ }^{13}$ The findings of this analysis suggest that the price-decreasing effect of multi-market participation may dominate the priceincreasing effect of greater concentration. In other words, reducing the number of independent providers through consolidation will allow for the internalization of demand externalities and possibly lower prices, ${ }^{14,15}$ despite reduced competition.

Concerns about the possible adverse effects of further consolidation among railroads, and the emergence of a "transcontinental railroad duopoly," in particular, ${ }^{16}$ recently led the Surface Transportation Board (STB) to revise its policies governing mergers and acquisitions. ${ }^{17}$ The STB noted that it "would require applicants in future merger proceedings to present proposals that enhance, not merely preserve, competition, in order to secure our approval." 18,19

The key premise underlying the STB's revised merger policy is apparently that reduced competition in the industry would necessarily lead to higher prices, in part, because the "efficiencies ... likely to be realized from further downsizing of rail route systems are limited." 20 The findings of this analysis suggest that further consolidation among railroads, even consolidation to a "transcontinental railroad duopoly," could potentially lead to lower prices even if such consolidation yields no additional merger economies. ${ }^{21}$

Similar issues arise with respect to commercial aviation in the United States. ${ }^{22}$ The poor financial health of several major airlines, including Delta and U.S. Airways ${ }^{23}$ can be

${ }^{12}$ According to the FCC, 276 million people, or 97 percent of the population in the U.S., live in counties in which there are 3 or more wireless providers. Approximately 250 million people, or 87 percent of the population in the U.S., live in counties in which there are 5 or more wireless providers. More than 216 million people, or 76 percent of the population in the U.S., can now choose from among 6 or more different wireless providers. Finally, 84 million people, or almost 30 percent of the population, live in counties served by 7 or more different wireless providers. See FCC (2004A, 949$)$. This increasing competition has led to a pronounced reduction in prices. For example, average revenue per minute declined from $\$ 0.47$ per minute in 1994 to $\$ 0.10$ at the beginning of 2003, a reduction of 79 percent. See FCC (2004A, 171 ).

${ }^{13}$ Latour et al. (2004) caution that "industry consolidation could lead to higher prices for consumers."

14 These are sometimes referred to as "network effects" or network externalities. See Liebowitz and Margolis (2002) for a comprehensive survey of the literature.

${ }^{15}$ Baranes and Flochel (2003) show that telecommunications carriers internalize call externalities for on-net calls, but not for off-net calls. The implication is that a merger between telecommunications carriers provides stronger incentives to internalize call externalities, ceteris paribus. Notably, this is the case even when there are interconnection agreements in existence prior to the merger.

${ }^{16}$ STB, 2001, p.43.

${ }^{17}$ As a result of consolidation, the number of Class I railroads in the U.S. declined from 40 in 1980 to 12 in 1993 (Association of American Railroads, 1981, p.2; 1994, p.3). [Class I railroads are defined by operating revenue thresholds that are adjusted annually for inflation. In 2002, a Class I railroad was defined as any railroad with at least $\$ 272$ million in annual revenues (Association of American Railroads, 2003, p.3)]. In 2003, there were only seven remaining Class I Railroads in the U.S. These are the Norfolk Southern, the Kansas City Southern, the Burlington Northern/Santa Fe, the Canadian National, the Soo Line (owned by the Canadian Pacific), the Union Pacific and CSX Transportation (STB, 2002, p.3).

${ }^{18}$ STB, 2001, p.10.

${ }^{19}$ The STB goes on to note that whereas their previous policy statement on mergers focused on "greater economic efficiency" and "improved service" as the most likely and significant public service benefits, the new policy statement adds enhanced competition as an important public interest benefit (STB, 2001, p.14). ${ }^{20}$ STB, 2001, p.14.

${ }^{21}$ In fact, despite significant consolidation in the railroad industry, inflation-adjusted, railroad rates have decreased by more than 45 percent since 1984 (STB, 2001, note 11).

${ }^{22}$ See Kahn (2004, chapter 2) for an insightful discussion of mergers and code-sharing alliances between the commercial airlines. 
expected to trigger merger activity in the very near future. Policymakers will naturally attempt to evaluate the trade-offs between increased market participation and multi-market participation in terms of airline profitability and rate structures. The analysis in this paper suggests that increased market concentration need not lead to higher prices if the disciplinary effect of multi-market participation is sufficiently pronounced. In other words, an exclusive focus on market concentration may lead policymakers astray.

\section{Conclusion}

This paper explores the trade-off between market concentration and multi-market participation in a Cournot model with complementary demands. A key finding is that mergers that increase both market concentration and multi-market participation can yield lower prices, higher profits and hence increase economic welfare despite the absence of merger economies. In other words, consumers can benefit from the integration of two complementary firms despite the reduction in competition per se.

These findings may have important implications for recent consolidation trends in network industries, including telecommunications and transportation. These industries exhibit demand complementarities and multi-market participation - characteristics that tend to bias traditional merger analysis against proposed mergers. More generally, this analysis underscores the fact that mergers in network industries raise complexities that may not be present in other industries..$^{24}$ It follows that antitrust practices that place undue weight on market concentration, particularly in network industries, can lead policymakers to block mergers that are actually welfare-enhancing.

\section{$5 \quad$ References}

Association of American Railroads (1981). Railroad Facts. Washington, DC: Association of American Railroads, Policy and Economics Department.

Association of American Railroads (1994). Railroad Facts. Washington, DC: Association of American Railroads, Policy and Economics Department.

Association of American Railroads (2003). Railroad Facts. Washington, DC: Association of American Railroads, Policy and Economics Department.

Baranes, E. and L. Flochel (2003) "Competition and Mergers in Networks with Call Externalities," Working Paper GATE 03-08.

Bernheim, D. and M. Whinston (1990) "Multimarket Contact and Collusive Behavior," The Rand Journal of Economics, 21: 1-26.

Brueckner, J. and T. Whalen (2000) "The Price Effects of International Airline Alliances," Journal of Law and Economics, 43: 503-545.

${ }^{23}$ See Carey (2004) and Peterson (2004).

${ }^{24}$ See Priest (2003) for a critique of the application of modern antitrust law to network industries. 
Bulow, J., J. Geanakoplos and P. Klemperer (1985) "Multimarket Oligopoly: Strategic Substitutes and Complements," The Journal of Political Economy, 93: 488-511.

Cabral, L. and M. Villas-Boas (forthcoming) "Multiproduct Oligopoly and Bertrand Supertraps," Management Science.

Carey, S. (2004) "US Airways Files For Chapter 11 A Second Time," The Wall Street Journal, September 13, p.A1.

Cellular Telecommunications and Internet Association (CTIA). http://www.ctia.org/.

Cellular Telecommunications and Internet Association (CTIA). "Semi-Annual Wireless Industry Survey," http://www.ctia.org/public_policy/statistics/index.cfm/AID/10030 (2004).

Champsaur, P. and J. Rochet (1989) "Multiproduct Duopolists," Econometrica, 57: 533557.

Dreazen, Y. (2002) "FCC, Faced With Telecom Crisis, Could Let a Bell Buy WorldCom," The Wall Street Journal, July 15, p.A1.

Economides, N. and S. Salop (1992) "Competition and Integration Among Complements, and Network Market Structure," The Journal of Industrial Economics, Volume XL: 105123.

Evans, W. and I. Kessides (1994) "Living by the "Golden Rule: Multimarket Contact in the U.S. Airline Industry,” The Quarterly Journal of Economics, 109: 341-366.

Farrell, J. and C. Shapiro (1990) "Horizontal Mergers: An Equilibrium Analysis," The American Economic Review, 80: 107-126.

Federal Communications Commission, Annual Report and Analysis of Competitive Market Conditions With Respect to Commercial Mobile Services, Ninth Report. WT Docket No. 04-111, September 28, 2004A.

Federal Communications Commission, In the Matter of Applications of AT\&T Wireless Services, Inc. and Cingular Wireless Corporation For Consent to Transfer Control of Licenses and Authorizations, WT Docket No. 04-70, October 26, 2004B.

Grimm, C. and C. Winston (2000) "Competition in the Deregulated Railroad Industry: Sources, Effects, and Policy Issues," in Sam Peltzman and Clifford Winston (ed.) Deregulation of Network Industries. Washington, D.C.: AEI-Brookings Joint Center For Regulatory Studies.

Hughes, K. and C. Oughton (1993) "Diversification, Multi-market Contact and Profitability," Economica, 60: 203-224.

Jamison, M. (2002) "Network Externalities, Mergers and Industry Concentration," mimeo, University of Florida. 
Kahn, A. (2004) Lessons from Deregulation: Telecommunications and Airlines after the Crunch. Washington D.C.: AEI-Brookings Joint Center For Regulatory Studies.

Larson, A., D. Lehman, and D. Weisman (1990) "A General Theory of Point-to-Point Long-Distance Demand," in A. de Fontenay, M.H. Shugard and D.S. Sibley (ed.) Telecommunications Demand Modelling. Amsterdam: North-Holland Publishing Co.

Latour, A., J. Drucker, R. Sidel and A. Raghavan (2004) "Cingular Deal Will Reshape Industry," The Wall Street Journal (On-Line Edition), February 17.

Lehman, D., and D. Weisman (2000) The Telecommunications Act of 1996: The "Costs" of Managed Competition. Boston MA: Kluwer Academic Publishers.

Liebowitz, S. and S. Margolis (2002) "Network Effects," in Martin Cave, Sumit Majumdar, and Ingo Vogelsang (ed.) Handbook of Telecommunications Economics. Amsterdam: North-Holland Publishing Co.

Morrison, S. and C. Winston (2000) "The Remaining Role for Government Policy in the Deregulated Airline Industry," in Sam Peltzman and Clifford Winston (ed.) Deregulation of Network Industries. Washington D.C.: AEI-Brookings Joint Center For Regulatory Studies.

Park, J., M. Babcock, K. Lemke and D. Weisman (2001) "Simulating The Effects of Railroad Mergers," Southern Economic Journal, 67: 938-953.

Peterson, B. (2004) "Take Your Seats and Prepare For Bankruptcy," The Wall Street Journal, September 21, p.B2.

Phillips, O. and C. Mason (1996) "Market Regulation and Multimarket Rivalry," The Rand Journal of Economics, 27: 596-617.

Priest, G. (2003) "Flawed Efforts to Apply Modern Antitrust Law to Network Industries," in Robert Hahn (ed.) High Stakes Antitrust: The Last Hurrah? Washington D.C.: AEIBrookings Joint Center For Regulatory Studies

Surface Transportation Board Decision (2001) SBC Ex Parte No. 582 (Sub-No.1), Major Rail Consolidation Procedures, June 11.

Surface Transportation Board (2002) Office of Economics, Environmental Analysis, and Administration, Statistics of Class I Freight Railroads in the United States for the Year Ended December 31.

Taylor, L. (1994) Telecommunications Demand In Theory and Practice. Boston MA: Kluwer.

The Wall Street Journal (2004) "Cingular Closes Merger with AT\&T Wireless," October 26.

Tirole, J. (1988) The Theory of Industrial Organization. Cambridge MA: MIT Press. 
U.S. Department of Justice and the Federal Trade Commission. Horizontal Merger Guidelines. [Inclusive of April 8, 1997 Revisions] (1992).

Weisman, D. (1999) "Footprints In Cyberspace: Toward A Theory of Mergers In Network Industries," Info, 1: 305-308.

Weisman, D. (2003) "A Generalized Pricing Rule for Multi-Market Cournot Oligopoly," Economics Letters, 81: 95-99. 